\title{
Células: do mundo invisível ao mundo real
}

Cells: from the invisible world to the real world

Bruno Pinheiro Gomes ${ }^{1}$, Iara Belink Hell ${ }^{2}$, Karina Carvalho Mancini ${ }^{3}$, Luiz Fernando

Duboc $^{3}$

${ }^{1}$ Programa de Pós-graduação em Ensino de Biologia em Rede Nacional (PROFBIO), Universidade Federal do Espírito Santo, São Mateus, Espírito Santo, Brasil.

${ }^{2}$ Programa de Pós-graduação em Ensino na Educação Básica (PPGEEB), Universidade Federal do Espírito Santo, São Mateus, Espírito Santo, Brasil.

${ }^{3}$ Universidade Federal do Espírito Santo, Departamento de Ciências Agrárias e Biológicas, São Mateus, Espírito Santo, Brasil.

Autor para correspondência: Bruno Pinheiro Gomes

EEFM José de Caldas Brito

Rua Amapá, 1896, Interlagos, CEP 29.903-650, Linhares, Espírito Santo, Brasil

Tel: +55 27 99727-6900

Email: biopgmodelosdidaticos@gmail.com

Submetido em 20/12/2020

Aceito em 21/12/2020

Health and Biosciences, v.1, n.3, Dez. 2020

Disponível em: https://periodicos.ufes.br/healthandbiosciences 


\title{
RESUMO
}

O trabalho trata-se de uma proposta de atividade investigativa sobre o tema Citologia para as aulas de Biologia do ensino médio, tendo como objetivo investigar a célula animal e suas organelas, correlacionando suas funções, além de construir modelos didáticos de células animais utilizando materiais como parafina e biscuit. Apresenta metodologia detalhada e informações sobre como explorar a atividade numa abordagem investigativa. A atividade foi desenvolvida em uma turma da EJA e os resultados foram muito relevantes, haja vista a interação entre os alunos e seu envolvimento durante os momentos das atividades. A atividade descrita se torna possível mesmo diante de sérias limitações, pois necessita de materiais de fácil aquisição e baixo custo, produção rápida e pode ser realizada em locais da própria escola. Os resultados quanto à aprendizagem são extremamente satisfatórios, compensando qualquer esforço.

Palavras-chave: Biologia. Citologia. Modelos Didáticos. Atividade Investigativa. Ensino

\begin{abstract}
The work is a proposal for an investigative activity on the subject of Cytology for high school Biology classes aiming to investigate the animal cell and its organelles correlating their functions, in addition to building didactic models of animal cells using materials such as paraffin and cold porcelain clay. It presents detailed methodology and information on how to explore the activity in an investigative approach. The activity was developed in an EJA class and the results were very relevant, considering the interaction between the students and their involvement during the moments of the activities. The described activity becomes possible even in the face of serious limitations, as it requires materials that are easy to acquire and low cost, fast to produce and can be carried out at school locations. Learning outcomes are extremely satisfactory, making up for any effort.
\end{abstract}

Keywords: Biology. Cytology. Didactic Models. Investigative Activity. Teaching.

Health and Biosciences, v.1, n.3, Dez. 2020

Disponível em: https://periodicos.ufes.br/healthandbiosciences 


\section{INTRODUÇÃO}

O ensino de Citologia na Educação de Jovens e Adultos - EJA, é realizado na segunda etapa, que equivale a segunda série do Ensino Médio. Essa modalidade de ensino sofreu modificações em sua estrutura no estado do Espírito Santo, passando a ser oferecida em modelo semipresencial. Sendo assim, a disciplina de Biologia só possui uma aula presencial por semana, durante um semestre, na etapa citada, restringindo ainda mais o tempo de hora/aula. Neste contexto, para abordagem de conteúdos com uma complexidade mais elevada, como é o caso da Citologia, principalmente por se tratar do mundo microscópico, abstrato para a maioria das pessoas, se faz necessário o emprego de metodologias extremamente didáticas, provenientes de um planejamento específico para este público-alvo. Segundo Moura (1999), na EJA deve ser incluída a prática sem improviso, a qual deve resultar de um planejamento de acordo com a realidade do aluno.

Não há dúvidas quanto à importância do ensino de Citologia, pois este se configura como base para compreensão de inúmeros conceitos, entre eles Evolução, Genética, Histologia, Fisiologia, Embriologia e Anatomia. Apesar de tão importante, na percepção de muitos alunos, ela é considera abstrata. A abstração trazida pela Citologia requer um esforço maior para que a significação conceitual de temas como estrutura e função da célula, por exemplo, possa levar a uma maior reflexão por parte dos alunos (KUPSKE \& HERMEL, 2015).

Segundo Demo (2002), a envolvência comprometida é essencial para que haja aprendizado, ou seja, nós professores precisamos estar inteiramente engajados no processo e provocar esse engajamento em nossos alunos, possibilitando uma aprendizagem significativa.

O conhecimento é significativo por definição. É o produto significativo de um processo psicológico cognitivo ("saber") que envolve a interação entre ideias "logicamente" (culturalmente) significativas, ideias anteriores ("ancoradas") relevantes da estrutura cognitiva particular do aprendiz (ou estrutura dos conhecimentos deste) e o "mecanismo" mental do mesmo para aprender de forma significativa ou para adquirir e reter conhecimentos (AUSUBEL, 2003).

$\mathrm{O}$ processo educativo requer uma aprendizagem significativa que atenda à aprendizagem de conceitos de modo que ao ensinar, o professor apresente significados contextuais aos alunos e que estes possam compreendê-los, ancorando-se em conceitos já estabelecidos cognitivamente e possam posteriormente compartilhá-los (LIMA et al., 2012).

Health and Biosciences, v.1, n.3, Dez. 2020

Disponível em: https://periodicos.ufes.br/healthandbiosciences 
Sendo assim, é imprescindível a construção do conhecimento de forma conjunta, em que o professor assume o papel de mediador junto aos seus alunos, e estes atuem ativamente no processo com suas contribuições. Nesta perspectiva surge a ideia da atividade prática investigativa de construção de um modelo didático representando uma célula animal.

\section{OBJETIVOS}

$\checkmark$ Investigar a célula animal e suas organelas correlacionando suas funções.

$\checkmark$ Construir modelos didáticos de células animais utilizando materiais como parafina e biscuit.

\section{METODOLOGIA}

\section{Materiais utilizados}

- Vídeo: Biology: Cell Structure (Organelas: estrutura celular). Disponível em: https://www.youtube.com/watch?v=URUJD5NEXC8\&list=PLFtIFq21Aov3WqX5L4D uVMGvqsu0hxJ\&index $=1$;

- Texto: Organelas celulares e suas funções: como sua cidade pode te ajudar. Site Vestibular. Disponível em: https://www.vestibular.com.br/dica/organelas-celulares-esuas-funcoes-como-suacidade-pode-te-ajudar/;

- Pratos plásticos (foram utilizados 5 pratos de $25 \mathrm{~cm}$ de diâmetro e $5 \mathrm{~cm}$ de altura, mas fica a critério do professor, conforme a quantidade de alunos);

- Biscuit (para um modelo são necessários 8 pacotes de $90 \mathrm{~g}$ de cores distintas sendo possível misturar massas para formar novas cores. Ainda, é possível comprar massa natural e colorir com tinta de tecido de cores distintas);

- Ferramentas para o manuseio do biscuit: rolo de plástico para abrir massa (pode ser substituído por um pedaço de cano, de $20 \mathrm{~cm}$ ), folhas de EVA para evitar que a massa grude (1 por grupo);

- Parafina (a quantidade varia, pois deve-se levar em consideração as dimensões do prato. Por exemplo, se usar velas, serão necessários cerca de 5 pacotes de velas $n^{\circ} 5$, com 24 unidades cada, para preencher um prato de $25 \mathrm{~cm}$ de diâmetro e $5 \mathrm{~cm}$ de altura. Uma dica é a produção de uma como teste);

Health and Biosciences, v.1, n.3, Dez. 2020

Disponível em: https://periodicos.ufes.br/healthandbiosciences 
- Giz de cera para tingir o citoplasma (opcional - 1 giz pequeno (24 g), é o suficiente para tingir o citoplasma de 1 célula);

- Fonte de calor: Fogareiro portátil, aquecedor de imersão, bico de Bunsen ou forno microondas;

- Recipiente para derreter a parafina;

- Imagens de células animal e organela (a serem utilizadas com referência no momento da produção).

\section{Desenvolvimento}

Sugere-se que a atividade ocorra em 4 momentos correspondendo a 7 aulas de 55 minutos cada, a saber:

$\underline{1^{\circ} \text { momento: }}$ Imaginando e ilustrando as células (1 aula de $55 \mathrm{~min}$ ).

Para realização desta primeira aula faz-se necessária a organização do tempo para distribuição das diversas atividades. Para iniciar, sugere-se que o professor escreva no quadro branco o título "desvendando as células". Os 20 minutos seguintes seriam destinados à produção de desenhos sobre as células. Em busca de apurar os conhecimentos prévios dos alunos sobre o tema, o professor deve orientá-los a desenhar uma célula e todas as estruturas que imaginem que ela possua. Ainda, é importante sugerir, se considerarem necessário, o acréscimo dos nomes e descrições que possam auxiliar na identificação. Finalizando esta primeira etapa os alunos deverão guardar os desenhos consigo para uso posterior.

Na sequência, sugere-se que os alunos assistam ao vídeo 'Biology: Cell Structure (Organelas: estrutura celular)' com duração de 7 minutos (e o professor deve remover o áudio, uma vez que está em inglês), o qual apresenta organelas em pleno funcionamento. A partir do vídeo, os alunos conheceriam um pouco sobre as organelas e suas funções, porém ainda sem muitas informações. Afinal, foram removidos legenda e áudio durante a reprodução do vídeo. Para finalização da aula propõe-se que os alunos façam questionamentos acerca do vídeo promovendo uma tempestade de ideias. Para isso, o professor mediador deve apresentar o problema norteador, como por exemplo "o que existe em uma célula e como elas funcionam?", e a partir daí desenvolver a atividade. É importante que os alunos saiam com a expectativa da próxima aula. 
$\underline{2^{\circ} \text { momento: }}$ Construindo e discutindo hipóteses sobre as células (1 aula de $55 \mathrm{~min}$ ).

A turma deverá ser dividida em grupos (entre 4 e 6 integrantes), que trabalharão juntos para desvendarem os mistérios das células.

Inicialmente, os alunos deverão responder aos seguintes questionamentos: "De que maneira acontece o transporte de substâncias dentro das células?”, "Como as células conseguem energia?”, “Como a célula recicla seus componentes?", “Como a célula controla o que entra e o que sai dela?".

Logo após, os grupos deverão socializar suas respostas e argumentar sobre suas ideias. Todo este momento de troca de saberes deve ser mediado pelo professor regente, que a todo o momento precisa estar atento ao desenrolar das discussões.

A partir daí, em grupo, serão construídas hipóteses que visem responder a tais questionamentos sobre as organelas e suas principais funções. Tendo concluído as hipóteses, cada grupo receberá uma cópia do texto "Organelas celulares e suas funções: como sua cidade pode te ajudar" do site vestibular, e fazer a sua leitura. A partir dele, os grupos chegarão às conclusões e respostas acerca das hipóteses criadas.

Finalizando este momento os alunos deverão retomar ao desenho produzido na aula anterior. Em um momento de análise, eles precisarão verificar se fariam alguma modificação em sua célula, acrescentando ou retirando estruturas. Poderá ser ofertada oportunidade para que compartilhem suas sugestões com toda a turma.

Durante essa troca de saberes, haverá uma breve introdução aos conceitos, em paralelo às falas emitidas pelos grupos.

30 momento: Aquisição dos materiais e produção das organelas e estruturas celulares (2 aulas de $55 \mathrm{~min})$.

Tendo trabalhado com perguntas, hipóteses, análise e discussão, chegou o momento da construção do modelo didático.

Para isso, será necessário se ter em mãos os materiais já descritos (exceto parafina, giz de cera, recipiente e fonte de calor), para produção das organelas. Deve-se reservar imagens de referência e levar para os alunos utilizarem durante a produção.

De acordo com o número de alunos é importante dividir a turma em grupos, para facilitar o trabalho, além de se utilizar um ambiente como o laboratório de Biologia (se houver) ou um espaço que possua mesas grandes (como o refeitório).

Health and Biosciences, v.1, n.3, Dez. 2020

Disponível em: https://periodicos.ufes.br/healthandbiosciences 
Propõem-se a produção das seguintes organelas e estruturas celulares: núcleo e material genético, retículo endoplasmático liso, retículo endoplasmático rugoso, complexo de Golgi, lisossomos, mitocôndrias e ribossomos. Os grupos podem dividir a produção das organelas por integrantes, assim conseguirão concluir a confecção durante as aulas. É importante se atentar quanto aos tamanhos de cada estrutura, assim aconselha-se ter em mãos o prato que será a base para fazer as medições. Neste momento é interessante que o professor também construa as organelas junto aos alunos.

Tendo concluído as produções, as organelas precisam secar à temperatura ambiente por no mínimo 24 horas (Figura 1). Utilize a folha de EVA como base.

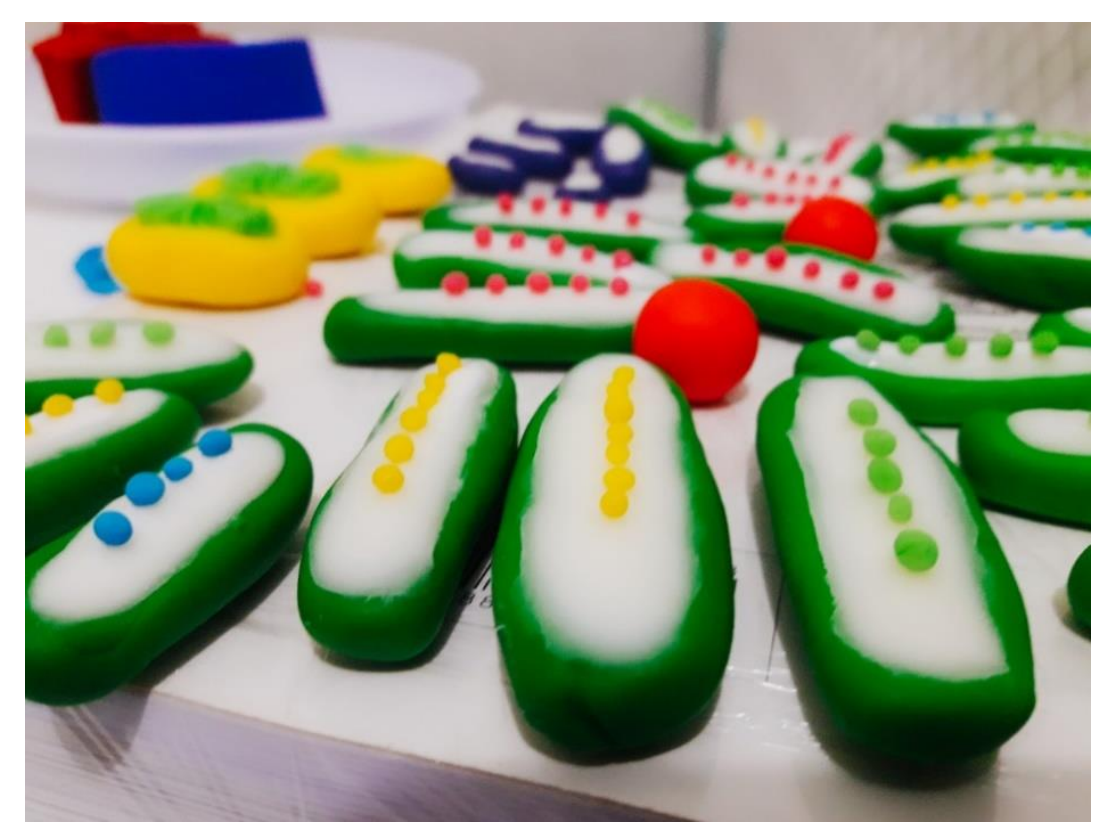

Figura 1. Organelas no processo de secagem.

4 momento: Produção do citoplasma (2 aulas de 55 min).

Depois de produzir as organelas, agora é hora de organizá-las no citoplasma de maneira que possam formar a célula e cumprir suas funções. O desenvolvimento desta parte também deverá ser realizado em um espaço equipado (laboratório) ou aberto.

Os grupos deverão ter em mãos os pratos, as organelas e a parafina, que primeiramente deverá ser derretida. Para isso, faz-se necessária a utilização de uma fonte de calor (citada em “materiais utilizados") que deve ser utilizada pelo professor ou alguém que o possa auxiliar,

Health and Biosciences, v.1, n.3, Dez. 2020

Disponível em: https://periodicos.ufes.br/healthandbiosciences 
evitando possíveis acidentes. Para quem optar por tingir o citoplasma com giz de cera, este deve ser derretido junto à parafina.

Ao derreter a parafina, deve-se despejar um pouco no prato, com $2 \mathrm{~cm}$ de altura, para fixar as organelas maiores, como núcleo, retículo endoplasmático liso e retículo endoplasmático rugoso. Na sequência, aos poucos e com cuidado, despeja-se o restante da parafina, colocando e distribuindo as demais organelas sem submergi-las. Neste momento, é importante utilizar imagens de referência para orientação quanto à distribuição das organelas.

Tendo finalizado o citoplasma e a fixação das organelas (Figura 2), as células deverão ser deixadas para secar até a próxima aula, para então serem desenformadas, se necessário.

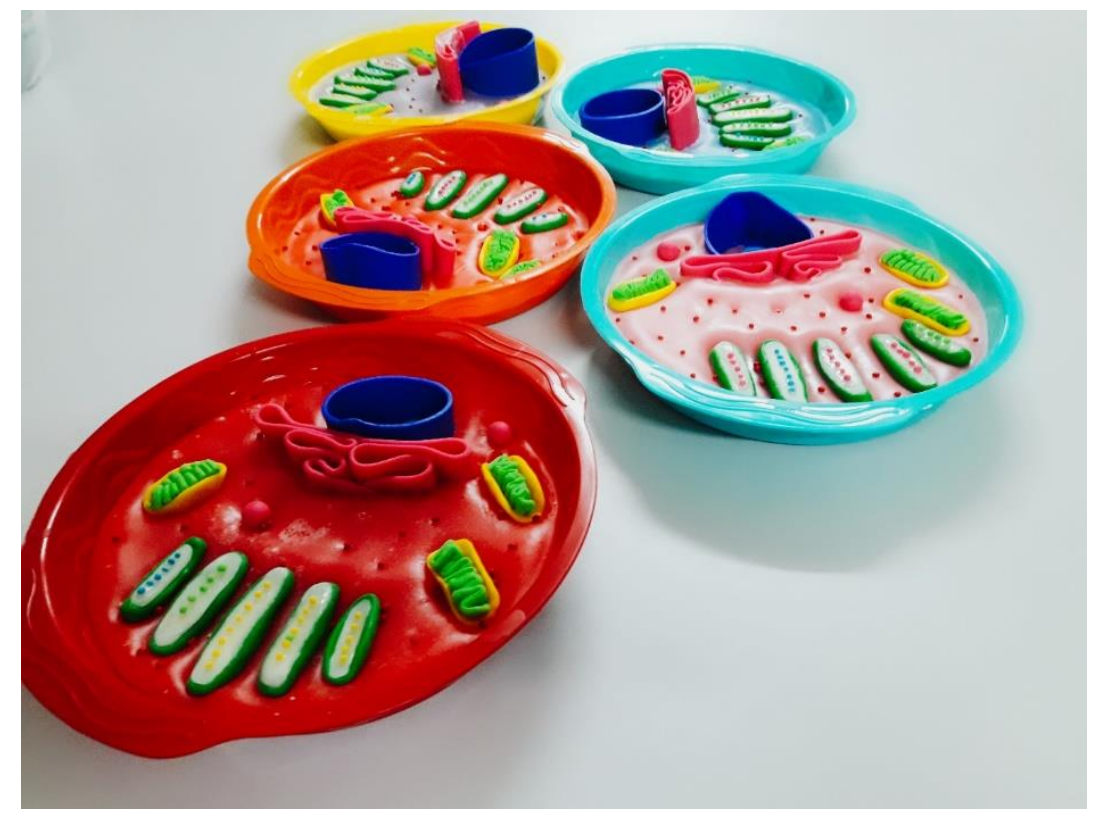

Figura 2. Células produzidas pelos alunos.

50 momento: Socialização dos conhecimentos (1 aula de $55 \mathrm{~min}$ ).

Estando concluídos os modelos didáticos das células, chegou o momento de utilizá-los na troca de saberes. Cada grupo deverá apresentar rapidamente sua célula, destacando suas organelas e funções. As apresentações deverão estar relacionadas aos questionamentos feitos no $3^{\circ}$ momento, ficando cada grupo responsável por pelo menos um deles. Após isso, com a mediação do professor, discussões devem ser provocadas, levando os alunos a dialogarem sobre a construção do conhecimento a partir dos modelos, correlacionando com todas as fases do processo. É um momento oportuno para se ouvir as opiniões e experiências, além de finalizar a 
avaliação de todo processo.

\title{
PONTOS INVESTIGATIVOS DA ATIVIDADE
}

O ensino por investigação sem dúvida é uma metodologia de grande potencial a ser integrado na Educação do século XXI.

\begin{abstract}
Tomando-o associado ao trabalho do professor e não apenas a uma estratégia específica, o ensino por investigação configura-se como uma abordagem didática, podendo, portanto, estar vinculado a qualquer recurso de ensino desde que o processo de investigação seja colocado em prática e realizado pelos alunos a partir e por meio das orientações do professor (SASSERON, 2015, p. 58).
\end{abstract}

Nesta proposta didática, entre os pontos investigativos a serem destacados estão as produções dos alunos sobre as células, utilizando os seus conhecimentos prévios gerados no $1^{\circ}$ momento, onde os alunos deveriam desenhar uma célula e suas organelas a partir de seus conhecimentos. Ainda neste momento, as discussões com base no vídeo apresentado também fazem parte da construção investigativa em função da resolução de problemas coletivamente.

Como abordagem didática, o ensino por investigação demanda que o professor coloque em prática habilidades que ajudem os estudantes a resolver problemas a eles apresentados, devendo interagir com seus colegas, com os materiais à disposição, com os conhecimentos já sistematizados e existentes (SASSERON, 2015).

No $2^{\circ}$ momento, a construção de hipóteses referente aos questionamentos propostos faz parte do momento investigativo da atividade. Por meio da leitura do texto, os grupos puderam buscar respostas e propor soluções aos problemas.

Já nos $3^{\circ}$ e $4^{\circ}$ momentos, da produção das organelas e citoplasma, os alunos deveriam utilizar seus conhecimentos para produzi-las. Mas o destaque é quanto aos questionamentos que surgem durante a produção, com os alunos recorrendo ao professor mediador para sanar as dúvidas, o que torna esse momento investigativo de construção entre alunos e professor.

$\mathrm{O}$ último momento $\left(\mathrm{o} 5^{\circ}\right.$ ), foi reservado para conclusão da atividade. As apresentações dos grupos, relacionadas às perguntas, propiciaram a troca de saberes. Cada grupo pode expor os conhecimentos adquiridos e suas considerações. Com isso, foi possível finalizar a atividade investigativa de forma exitosa.

Health and Biosciences, v.1, n.3, Dez. 2020

Disponível em: https://periodicos.ufes.br/healthandbiosciences 


\section{CONSIDERAÇÕES}

Como relatado, a atividade foi desenvolvida em uma turma da EJA, o que já é um diferencial. Mas fica como sugestão a aplicação em outras séries, tanto do ensino fundamental quanto do médio. Os resultados foram muito relevantes, como relatado pelos próprios alunos em suas experiências, os quais até competiam para ver quem levaria o modelo para casa.

Pode-se destacar a interação entre os alunos e seu envolvimento durante os momentos das atividades, sendo que tudo isso foi evidenciado durante a avaliação qualitativa e também na quantitativa (provas e atividades avaliativas).

Na realidade ora apresentada, o ponto negativo de destaque é a ausência de um espaço físico apropriado, como um laboratório, o que limitou a execução das atividades à sala de aula. A utilização de um fogareiro portátil para o derretimento da parafina gerou um pouco de fumaça, o que acaba criando incômodos em outros espaços da escola.

Foram utilizadas caixas de velas, mas sugere-se sua substituição por parafina em flocos, caso possível, devido ao menor custo e a maior facilidade de manuseio.

Esta atividade prática não se limita a produção de uma célula animal, podendo ser adaptada aos outros tipos celulares.

De modo geral, essa é uma atividade prática que se torna possível mesmo diante de limitações, pois necessita de materiais de fácil aquisição e baixo custo, produção rápida e pode ser realizada em locais da própria escola. Os resultados quanto à aprendizagem são extremamente satisfatórios, compensando qualquer esforço.

\section{AGRADECIMENTOS}

O presente trabalho foi realizado com o apoio da Coordenação de Aperfeiçoamento de Pessoal de Nível Superior - Brasil (CAPES) - Código de financiamento 001.

\section{REFERÊNCIAS BIBLIOGRÁFICAS}

1. AUSUBEL DP. Aquisição e Retenção de Conhecimentos: Uma Perspectiva Cognitiva, Lisboa: Plátano, 2003, 243p.

Health and Biosciences, v.1, n.3, Dez. 2020

Disponível em: https://periodicos.ufes.br/healthandbiosciences 
2. BIOLOGY: Cell Structure. Nucleus Medical Media. Geórgia, 2015. Disponível em: https://www.youtube.com/watch?v=URUJD5NEXC8\&list=PLFtIFq21Aov3WqX5L4Du VMGvqsu0hxJ\&index=1. Acesso em 09 de Junho de 2020.

3. DEMO P. Educação e conhecimento. Relação necessária, insuficiente e controversa, 3.ed., Petrópolis: Vozes, 2002, 183p.

4. KUPSKE C, HERMEL EES. Concepções sobre biologia celular de alunos ingressantes em um curso de licenciatura em Ciências Biológicas. In: III Congresso Internacional de Educação Científica e Tecnológica. Anais do CIECITEC, Santo Ângelo, 2015. v.3.

5. LIMA JMM, AYUB CLSC, MORALES AG, LORENCINI JUNIOR A. Aproximação entre a teoria histórico-crítica e a Aprendizagem Significativa: uma prática pedagógica para o Ensino de Biologia. AS em Revista 2(2): 54-64, 2012.

6. MOURA TMM. A prática pedagógica dos alfabetizadores de jovens e adultos: contribuições de Freire, Ferreiro e Vygotsky. Maceió: EDUFAL/INEP, 1999, 229p.

7. SASSERON LH. Alfabetização Científica, Ensino por Investigação e Argumentação: relações entre Ciências da Natureza e escola. Rev Ensaio 17: 49-67, 2015.

8. VESTIBULAR. Organelas celulares e suas funções: como sua cidade pode te ajudar. Vestibular, São Paulo. Disponível em: https://www.vestibular.com.br/dica/organelascelulares-e-suas-funcoes-como-suacidade-pode-te-ajudar/. Acesso em 09 de junho de 2020.

Health and Biosciences, v.1, n.3, Dez. 2020

Disponível em: https://periodicos.ufes.br/healthandbiosciences 